Mericg $V$.

Rev. Chll. Pedlatr. 64 (1); 40-43, 1993

\title{
Convulsiones y paro cardíaco: forma inhabitual de presentación de miocarditis asociada a virus de Epstein Barr
}

\author{
Verónica Mericq G.'; Jaime Cordero 'T.1
}

\section{Epstein Barr virus myocarditis}

The incidence of carditis in infeclious mononucleosis is low. Clinical manifestations of heart involvement include electrocardiographic changes in $6 \%$ and cardiac symptoms in $0.7 \%$ of confirmed cases. A previously healkhy 9 year old boy came to the emergency room of a melropoliton children's hospilal at Santiago. Chile, because of generalized tonic seizures, which did not respond to phenoburbital and neither lo diazepam. He wos hansferred to the intensive care unit in como, score $3 \mathrm{by}$ Glasgow Scole, wilh iregular bradicardio and recurrent apneo. He was conected lo mechanical ventilotion. His cardiac moniloring, showed complete alriovenlricular block with altial rate 150 ; min and ventricular rale 53: min. He hod five episodes of asysiole, requiring cordiorespiratory resuscifotion, isoproferenol, dopanine ond prednisone. His course was critical with hypotension, persisting AV block ond, 24 hours after admission hod a new periad of asystole: an external pacemaker was then installed. Chest $x$ ray showed hearl enlargement. Echocardiographic findings included right atrial and ventricular dilation, wall ederna and lowered left ventriculor performance. Serum creatine phosphokinase aclivity was $190 \mathrm{U} / 1$ al admitance and $29 \mathrm{~V} / \mathrm{l}$ six doys later, while serum levels of muscle brain isoenzime were $53 \mathrm{U} / 1$ and $22 \mathrm{U} / 1$ respectively, thus suggesting myocordial injury. Serological investigations for echo and coxsackie viruses were negative. Epslein Bar virus anticapside igM an arrival and at doy ten alfer admission was $1 / 40$ highest dilution titlel. Creactive prolein $6 \mathrm{mg} / \mathrm{l}$, erithrocite sedimentotion rate $10 \mathrm{~mm} / \mathrm{h}$, search for rheumaloid factor gave negative resulls. Isoproferenol was continued for three days, dopomine for nine days and external pacencker for 17 doys. He was dismissed at 18 days after admission without pharmacological ar electrical support, in slnus rhythen wilh isolated ventricular extrasystoles.

[Key wordst Myocorditis, Epstein Barr virus, complete heart block.]

La mononucleosis infecciosa es una enfermedad cuya incidencia se estima en $50 \cdot 100000$ habilantes: afio, su evolución es habitualmente benigna, aguda, autolimitada y sólo ocasionalmente se asocia a complicaciones severas o fatales. Entre las complicaciones descritas, estâ el compromiso cardíaco, que suele presentarse como anomalías electrocardiográficas, en $6 \%$ y síntomas cardíacos, en $0,7 \%$ de los pacientes ${ }^{1 \cdot 3}$. El espectro de síntomas es amplio, entre ellos arritmias, anomalías de la conducción y choque cardiogénico, entre otros.

Se describe el caso de un niffo de edad escolar, ел quien las primeras manifestaciones clínicas de enfermedad fueron convulsiones y cuyo estudio permitió identificar una miocarditis por virus de Epstein Barr.

3. Unidad de Cujdados Intensivos, Hospital Luis Calvo Mackenta.

\section{Caso clínico}

Varón de 9 años, sin antecedentes mórbidos de imporlancia, cualro días aptes del ingreso presentaba fiebre inlemitente de $39^{\circ} \mathrm{C}$, cefalea holocránea y vómitos explosivos asociados a dolor abóminal difuso. Consultó por crisis de hipertonía generalizada, desviación cefálica de la mirada y pérdida de conciencia en seis oponunidades en su casa, de un minuto de duración, con períodos intereríticos sin compromiso de conciencis, que se repitiejon tres veces en el servicio de urgencia a pesar del empleo de fenobstbital y diazepam a dosis habituales, por lo que se envió a la unidad de tratarniento intensivo, donde ingresó en coma profundo (Glasgow 3); ritmo cardíaco irregular, bradicardia y apneas, por lo que se le conectó a ventilación mecónica. Había ganglios occipitales palpables escasos, móviles, de $0,5 \cdot 0,5 \mathrm{~cm}$, faringe roja, hígado se palpaba $2 \mathrm{~cm}$ bajo el reborde costal; no se palpaba el bazo. En el electrocardiograma le frecuencia anticular era 150 - min y la ventricular 53 * min, con bloqueo aurículo ventricular completo. Sufrió cinco paros cardiacos que respondieton a masaje cardíaco, fue necesario indicarle isoproterenol $0,6 \mathrm{Hg} \cdot \mathrm{kg}$. min y dopamina $10 \mathrm{Hg} \cdot \mathrm{kg} \cdot \min$, mostraba tendencia a la hipotensión, a pesar de aporte de volúmenes apropiados de 


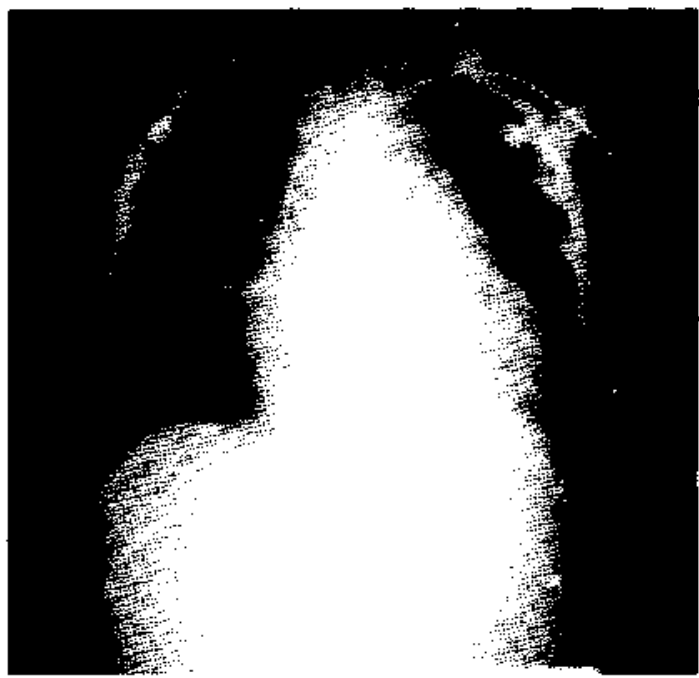

Figura 1: Radiogtafia torax de ingreso. Cardiomegalia global y catéler endocavitario de marcapaso cxterno en ventrículo derecho.

líujuidos, con mala respuesta a ambos. En cl hemograma de ingreso la seric roja era normal, con 15100 leucocitos, $7 \%$ baciliformes, $68 \%$ segmentados, $17 \%$ linfocitos y $8 \%$ monocilos, CPK 196 UA con fraccion MB de 53 U/. La radiografía de tórax registraba cardionegalia moderada (ligura 1). Con el ecocardiograma se detectó aumento de tamaño de la aurícula derecha $y$ venlriculo derecho, paredes engrosadas, fracción de acortamiento disminuida y discrelo derrame perjcárdico. Sc agregó prednisona $2 \mathrm{mg}$ * $\mathrm{kg}$ - día al tratamicnto. Evolucioń grave, con tendencia a la hipotensión arterial y acentuación del bloqueo atrioventricular, repitiendo a las 24 horas del ingreso el paro cardiaco, por lo que se instalo sonda marcapaso en el vcutrículo derecho. Los cullivos y pruebas serológicas para virus Echo y Coxsackic dieron resultados negativos. La Ig M para cápside de virus de Epstein Barr fue positiva en títulos $1 / 40$ al ingreso y a los 10 días. Proteína $C$ reactiva 6 mg $h_{+}$velocidad de sedimentación globular $10 \mathrm{~mm} / \mathrm{h}$ y factor reumatoídeo negativo. Scis días después del ingreso la crcatína fosfoquinasa sêrica era $29 \mathrm{U} / \mathrm{l}$ y la isoenzima músculo-cerebro (CPK ME) 22 U/. Mejoró lenta y progresivamente, al cabo de tres días fue posible suspender el apoyo cronótropo con isoprotercnol, manteniéndose la dopamina por nucve días. Postcriormente necesiló apoyo de marcapaso sólo en las noches, mientras los elecirocardiogramas mostraban mejoría progresiva de la conducción aurícalo ventricular, con alteraciones de la repolarización, aplanaoiento y desnivel de ST (figura 2). Al décimo día de hospitalización el ecocardiograma reveló que la conlracibibilidad ventricular era nomal y el sepum estaba discretamente engrosado. Al día décino sépimo de evolución se retiró la sonda marcapaso, cuando en el electrocardiograma se registraba titmo sinusal y exirasístoles aislados (figara 3). Sc dio de alta cl día 18 de hospitalización en bucnas condiciones generales.

\section{Comentario}

La mononucleosis infecciosa ocurre en todas las edades, siendo más frecuente en adultos jóvenes. En el jiño las manifestacioncs pueden ser atipicas. Entre sus complicaciones severas figuran la ruptura esplénica, el compromiso neuro16gico, anemia hemolítica sevcra, infecciones sobreagregadas y el compromiso miocárdico. La incidencia exacta del compromiso miocárdico es motivo de controversia, ya que el diagnóstico de miocardilis es difícil, por una seric de razones, entre ellos bajo indice de sospecha debido a su pequeña incidencia, signos clínicos y de laboratorio poco específicos y sensibles (taquicardia aislada, anomalias electrocardiográficas, simula-

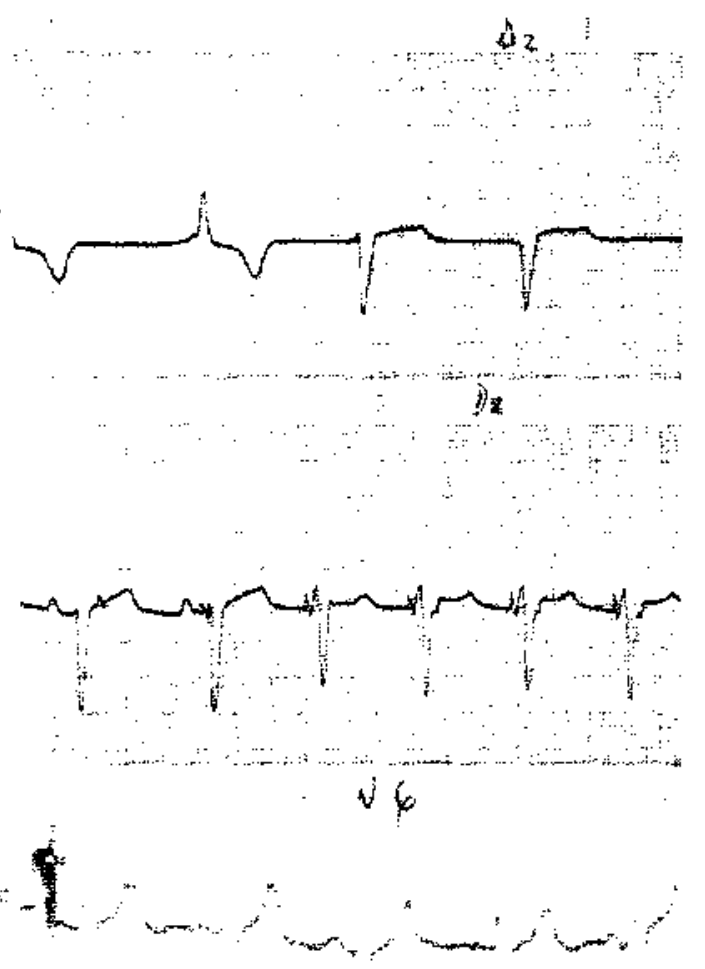

Figura 2: $D_{2}$ a) Ritmo idioventricular con frecuencia ventricular de $90 . D_{2}$ b) Bloqueo A-V completo con frecuencia auricular de 65 y frecuencia ventricular de $180 . V_{6}$ c) Trazado con ritmo aparentemente sinusal, con frecuencia auricalar de 100 y frecuencia ventricular de 100 . Ensanchamiento de QRS. 

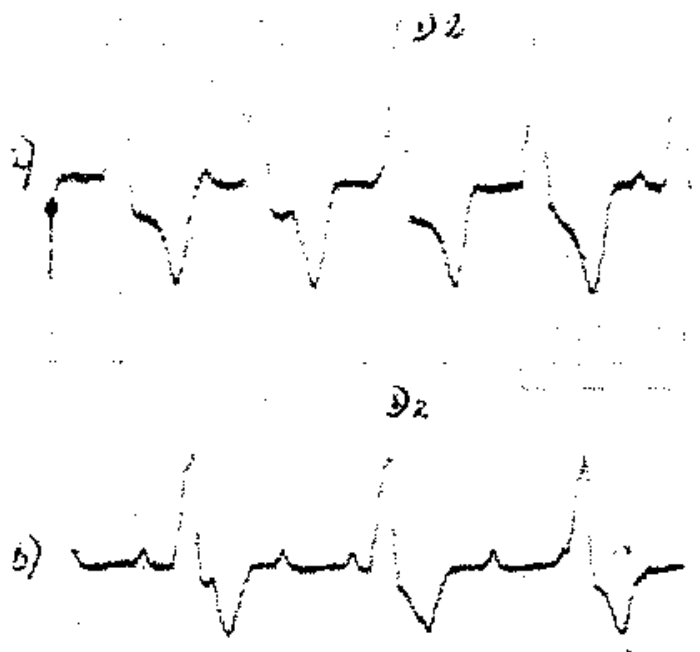

$A \vee F$

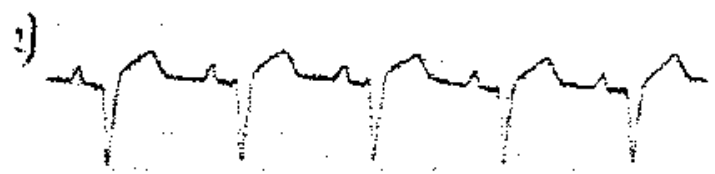

Figura 3: $D_{2}$ a) Se observa falta de activación auricular, sin secuencia de onda $P$, con ritmo idioventricular de $68 . D_{2}$ b) Ritao ventricular bien acoplado al marcapaso con frecuencia de 100. El primet complejo muestra captura ventricular de estímulo auricular propio. AVF c) Ritmo sinusal de $80 \mathrm{sin}$ marcapaso.

ción de infarto, choque cardiogénico, trastomos de la conducción) que avalen el diagnósticol-s.

En el caso que se comenta, el diagnóstico do miccarditis asociada a virus de Epstein Barr se basa en antecedentes de brusca descompensación cardíaca con crisis de Stokes Adams en un niño sano previamente, desde el punto de vista cardíaco; adenopatías y hepatomegalia; electrocardiograma con anomalías de la conducción evidentes, radiognafía de tórax con cardiomegalia. Aumento de CPK y CPK MB e IgM anticápside de virus de Epstein Barr en título máximo de dilución del laboratorio. No se dispone actualmente de un método confiable de diagnóstico y certificación etiológica de miocarditis, el que debe basarse en una alta sospecha clínica y el apo- yo de exámenes de laboratorio. La sensibilidad y especificidad de la biopsia endomiocárdica son muy variables, fluctuando entre 17 y $100 \%{ }^{6-9}$. Las lesiones de miocarditis por virus de Epstein Barr, descritas después de la muerte, se caracterizan por infiltración difusa inflamatoria, con células mononucleares en el tejido intersticial, a menudo de disposición perivascular, además de numerosas áreas de necrosis focal con infïltración mononuclear ${ }^{1}$. En algunas comunicaciones estos cambios parecen ser mayores en ventrículo derecho ${ }^{3}$. De esta falta de sensibilidad y especificidad también adolecen la ecocardiografía ${ }^{10} \mathrm{y}$ cintigrafía con galio"l. Actualmente se investigan nuevos procedimientos para el diagnóstico, aunque existen algunas miocarditis cuya presentación orienta a etiologías específicas ${ }^{12-14}$.

Para el tratamiento se recomienda terapia de soporte con reposo, oxigeno y drogas vasoaclivas, debido a la evolución generalmente autolimitada de la enfennedad, tal como en este caso. La utilidad de los inmunosupresores es aún discutida, con resultados no concluyentes y contradictorios $^{7.9}, 15$. En este paciente se usó prednisona en dosis antiinflamatorias e inmunosupresoras, en coincidencia con lo cual se observo mejoria de su trastomo de conducción en un plazo breve, lo que no asegura que ella sea atribuible al tratamiento.

Es importante destacar, de este caso, la forma de presentación como compromiso de conciencia con hipertonía generalizada, que obligan a considerar una amplia gama de diagnósticos diferenciales, sin olvidar la importancia que en tal caso tienen cl examen cardíaco, incluido un trazado electrocardiográfico y dentro del estudio etiológico clásico, la debida consideración al virus de Epstein Barr.

\section{Resumen}

La incidencia de compromiso cardíaco en la mononucleosis infecciosa es baja. El espectro de manifestaciones incluye cambios electrocardiogrăficos en $6 \%$ y síntomas cardíacos en $0,7 \%$ de los casos. Se describe el caso de un paciente de 9 años que ingresó al hospital por convulsiones tónicas generalizadas, que se repitieron a pesar del empleo de fenobarbital y diazepam. Fue admitido a tratamiento intensivo, en coma, grado 3 de Glasgow, con bradicardia irregular y apneas, 
bloqueo auriculoventricular completo, frecuencia auricular $150 / \mathrm{min}$ y ventricular $53 / \mathrm{min}$. Poco después de ingresar sufrió cinco paros cardíacos, requiriendo reanimación cardiopulmonar, ventilación mecánica, infusión de isoproterenol, dopamina y prednisona. Su evolución fue crítica con hipotensión y persistencia del bloqueo atrio ventricular. A las 24 horas de su ingreso se repitió la asistolía, por lo que se le instaló marcapaso extcmo. Los exámenes mostraron cardiomegalia en la radiografía de tórax; dilatación de la aurícula y ventrículo derecho, edema de pared y disminución de la contractilidad ventricular izquierda en la ultrasonografía cardiaca, concentraciones séricas de creatina fosfokinasa de $196 \mathrm{U} / \mathrm{con}$ fracción MB de 53 U/l. La serología y los cultivos para virus Echo y Coxsackie fueron negativos. La IgM anticapside de virus de Epstein Barr al ingreso y 10 días después fue positiva en título máximo de dilución (1/40), proteína $C$ reactiva 6 $\mathrm{mg} /$, velocidad de sedimentación de los eritrocitos $10 \mathrm{~mm} / \mathrm{h}$, factor resmató́deo negativo. El bloqueo cedió progresivamente, el isoproterenol pudo ser suspendido al tercer día, la dopamina al noveno y el marcapaso al décimo séptimo dia, siendo dado de alta 18 días después de ingresar con ritmo sinusal, extrasistoles ventriculares aislados, buena contractilidad ventricular y tasas normales de enzimas séricas.

(Palabras clave: Miocarditis, virus de Epstein Barr.)

\section{Referencias}

1. Miller $R$, Ward C, Amsterdam E, Mason DT, Celis $R$ : Focal mononucleosis myocarditis simulating myocardial infarction. Chest 1973; 63; 102-105.
2. Hoagtond $R$, Colonet $M C$ : Mononucleosis and heart disease. Am I Med Science 1964: 248: 35-40.

3. Marvin F and Howard $B$ : hean involvement in infeclious monknucleosis. Arch Intern Med 1958; 101; 636-644.

4. Frishman W, Krakss $M, Z a b k a r ~ J$, et ai.: Infectious mononucleosis and fatal myocarditis. Chesl $1977 ; 72$ : $535-538$

5. Tyson AA, Hackshaw BT, Kutcher $M$ : Acule Epstein Barr vinus myocarditis simulating myocandial infarction with cardiogenic shock. Southern Med J 1989; 82: 1184-1IBT.

6. Billingham $M$ : Acute Myocarditis. A diagnostic dilema, Br Heart J 1987; 58: 6-8.

7. Maisch B: Myocarditis Review. Current opintion in Cardiology 5, 1990; N 3: 320-327.

8. Mason J. Billingham M. Ricci D: Treatment of acute inflamatory myocarditis assisted by endomyocardial biopsy. An J Cardiol 1980; 45: 1037-1044.

9. Savoia M. Oxman M: Miocarditis, pericarditis, mediastinitis. En Mandell GL, Douglas RG, Bennet JE ed. Enfermedades Infecciosas. Príncipios y Práctica. Buenos Aires. Editorial Medica Panamericana 1991; 759.762 .

10. Pinnmoni A, Alberit $E$, Cigalouto $A$, el al: Echocardiographic findings in myocarditis. Am J Cardiol 1988; 62: 285-291.

11. Bouchour JA, Helias J, De Lajartre AY. et al.: Detection of myocarditis during the first year after discovery of a dilated candionyopathy by endomyocardial biopsy and gallium ${ }^{67}$ nyocardial scintigraphy: prospective multicenter French study of 91 patients. Eur Hest J 1988; $9: 520-528$.

12. Balimer PE. Hany A: Lyme Karditis. Schweiz Med Wochenschr 1988; $118 \div 358-362$.

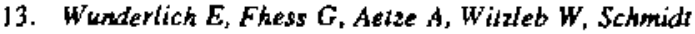
$P K H$ : Lyme Borreliose eine mögliche ursache von atrioventrikulären blockierungen. Z Kardiol 1988; 77 : 256-257.

14. Dec GW, Fallon JT, Southern JF, Palacios IF: Relation between histological findings on early repeat right ventricular biopsy and ventricular function in patients with myocarditis. Br Heart J 1988; 60: 322-337.

15. Gersh BJ: Infections: Myocsrditis. pericarditis and endocarditis. Editorial overview. Current opinion in cardiology 4, 1989: N 3: 403-407. 